\title{
SPECIAL PAPER \\ Intellectual developmental disorders in Mexico: a call for programmes promoting independence and inclusion
}

\author{
Gregorio Katz, ${ }^{1}$ Edgar Corona ${ }^{2}$ and Eduardo Lazcano-Ponce ${ }^{3}$
}

${ }^{1}$ General Director, Capacitación y Desarrollo Integral AC, Departamento de Psiquiatría Facultad de Medicina, Universidad Nacional Autónoma Universidad Nacional
de México, Mexico

${ }^{2}$ Student, David Geffen School of Medicine, University of California Los Angeles, Los Angeles, Los Angeles, LOS
California, USA

${ }^{3}$ Executive Director, Centro de Investigación en Salud Poblacional, Instituto Naciona de Salud Pública, Cuernavaca, Morelos, Mexico, email elazcano@insp.mx
This paper describes an innovative institution, Capacitación y Desarrollo Integral AC (CADI Comprehensive Training and Development), created in Mexico to develop evidence-based interventions grounded in the principles of inclusion, independence, social and health equity that promote the well-being of persons with intellectual developmental disorder older than 14 years.

Intellectual developmental disorder (IDD) is a neurodevelopmental disorder characterised by deficits in intellectual and adaptive functioning, which can lead to impairments in personal, social, academic and/or occupational abilities (Harris, 2013). According to a meta-analysis of 52 studies conducted in 42 countries, the prevalence of IDD is 10.37 per 1000 individuals (Maulik et al, 2011). In Mexico, it was estimated in 2008 that there were nearly 3 million people with IDD, a prevalence of roughly 25.44 per 1000 individuals (LazcanoPonce et al, 2008). Unfortunately, few rehabilitation programmes serve this population, and there is a lack of evidence-based services and healthcare guidelines. Manuals on psychiatric diagnosis focus on the identification only of serious IDD and this contributes to underreporting and inaccurate classification. Specifically in Mexico, the study of these disorders has not been a legal, social science or public health priority, and this has resulted in a dearth of scientific evidence. This is because the absence of policies promoting inclusion, respect of human rights, and non-discrimination inadvertently result in economic, social and political exclusion for persons with IDD (Huus et al, 2015). Specific competencies and guidelines are needed, as are interventions with a focus on prevention, rehabilitation, community integration and workforce inclusion (Lazcano-Ponce et al, 2008).

\section{The monopoly on disability care}

In Mexico, a government agency called the National Council for the Development and Inclusion of Persons with Disability (CONADIS) is responsible for ensuring the rights of persons with IDD. Unfortunately, CONADIS has limited infrastructure and financial and human resources. In the absence of comprehensive government policies, a private foundation in Mexico (Katz et al, 2008), Fundación Teletón, has monopolised the state resources allocated for persons with disabilities. In 17 years, Teletón has received in excess of US\$250 million, and an estimated one-third has come from public funds (Cabrera, 2010). Because of Teletón's lobbying, state governments have passed laws creating items in budgets specifically for Teletón, as if it were a government entity (Anuncian Moreno Valle y Teletón construcción de CRIT en Puebla, 2010). In other words, the Mexican government does not directly allocate funds for prevention and multidisciplinary management of patients with IDD, but instead enables a private entity to manage the public funds that do exist.

On 3 October 2014, the United Nation's Committee on the Rights of Persons with Disabilities (CRPD) issued a statement to the Mexican state after a thorough evaluation, which noted two critical points: (1) that a private entity (Fundación Teletón) absorbs many public resources allocated for IDD programmes; and (2) that it portrays persons with IDD as 'objects' of charity instead of 'subjects' with all the prerogatives of citizenship. Teletón's fundraising campaigns are televised and promoted broadly throughout Latin America. Although well intentioned, these campaigns fail to advocate for social equity and have become selfserving for the corporations that stand to benefit. The CRPD recommends that academic institutions and non-governmental organisations (NGOs) collaborate to implement prevention and control strategies, raise social awareness, and promote social equity.

\section{Capacitación y Desarrollo Integral AC}

In Mexico, an innovative institution called Capacitación y Desarrollo Integral AC (CADI Comprehensive Training and Development) was created 30 years ago to promote the well-being of adolescents with IDD by providing them with professional services (Allen-Leigh et al, 2008). CADI's model utilises a teaching strategy that promotes social and workforce integration; it provides life skills training for persons with IDD in low-income countries. It is a model that is internationally recognised as a community-oriented, evidencebased programme whose outcomes are specific and measurable, allowing them to be easily evaluated and assured for quality. Since its inception, CADI has served nearly 800 persons with IDD and made important achievements in the following areas.

\section{Raising awareness to change societal views}

Although no population-based studies have explored the societal exclusion that persons with IDD face, qualitative studies exploring social 
stigma in Mexico have demonstrated the need to educate families about how best to support their loved ones with IDD (Allen-Leigh, 2009). Social exclusion may occur when families institutionalise or seclude their relatives for fear of discrimination. Furthermore, when persons with IDD are allowed to work, they often hold low-pay, temporary jobs. We expect that the degree to which this occurs in Mexico is greater than in other countries, as government-led efforts to provide appropriate workforce training and to promote workforce and societal inclusion do not exist (Anderson et $a l, 2013)$. Clearly, societal and workforce exclusion both result in increased poverty and catastrophic expenses for families, and an important step forward, from both an economic and a human rights perspective, would address these points (Fujiura et al, 1994). Programmes in Mexico tend to propagate paternalistic ideals (see for instance the website of the Mexican Confederation of Organisations for Persons with Intellectual Disability, http://www.confe.org.mx). For example, the National System for Integral Family Development (DIF) is an intervention programme that does not allow the persons with IDD that it supports to leave their centre, which defeats the goals of an independent living programme. CADI's leadership works diligently to raise awareness of these issues in order to change societal perceptions of persons with IDD.

\section{Building best-practice models}

CADI's mission is oriented to both research and the community. This model attracted the attention of the World Health Organization (WHO), which invited CADI's director to join a group of international experts to modify the international nomenclature and classification of IDD-related diseases (ICD-11) (Carulla et al, 2011). Thus, CADI's evidence-based programme has had an enormous influence, as it promotes independence, social inclusion and improved quality of life. CADI's intervention covers skills development in four essential areas: academic-therapeutic practice; personal and social skills; work skills; and independent living (Katz \& Lazcano-Ponce, 2008). The programme is divided into three levels: initiation in independent living; community integration and social independence; and practical and psychological support. CADI accepts all persons with IDD into its programme, regardless of socioeconomic status, gender, ethnic group, sexual preference or religion.

\section{Promoting sustainable interventions}

Three sustainable funding mechanisms support CADI. First, CADI partners with companies to provide on-the-job skills training for persons under 18 years of age, in areas such as bakery, carpentry, paper recycling, packaging and assembly. Second, for the past 20 years, the DIF has provided financial support for CADI's evidence-based interventions, which have served almost 800 persons. Lastly, private companies also provide funding for
CADI. Thanks to these donations, CADI has built a facility that includes a dormitory, classrooms, an auditorium, cafeteria, gymnasium, bakery, medical office, dental office and small self-service shop. CADI also implemented a sustainable group model that incorporates an independent living and work skills programme, where individuals share an apartment and are employed.

\section{Demanding community integration}

CADI is one of the few organisations in Mexico seeking to address the social and workforce exclusion and poor quality of life of persons with IDD. One of the key ways in which CADI prepares persons with IDD for community integration is by developing academic and therapeutic practical skills among its participants. To do this, CADI collaborates with the local basic education services to generate specific academic certifications; this is the first time in all of Latin America that a strategy like this has been implemented. In March 2015, CADI graduated a class of participants from elementary and middle school, and they may now seek vocational job training or continue with high school.

\section{Multidisciplinary practice}

CADI's success has been in generating a multidisciplinary, evidence-based intervention that is grounded in the principles of inclusion, independence, and social and health equity. CADI relies on strong international, national and local partnerships, including those with the National Public Health Institute, Dr Juan N. Navarro Children's Psychiatric Hospital, the Mental Health Department of the Faculty of Medicine of the National Autonomous University of Mexico, the Mental Health Department of the University of Sydney and DIF. Public policy should focus on supporting collaborations like these.

\section{Conclusions}

CADI provides a community-oriented, evidencebased model that can be replicated throughout Mexico and other middle-income countries. The need to evaluate and report these procedures and construct CADI's practice guidelines as best practice remains but is recognised as a priority.

In Mexico, persons with IDD are often excluded from decisions that affect their daily lives, and government programmes that provide universal access to education, labour markets, public and health services are lacking. In Latin America persons with IDD are excluded from legislative, judicial, education, health and social agendas when they should be encouraged to advocate for themselves, just as persons without disabilities are. Few interventions seek to promote independence, social integration and workforce inclusion, and those that exist, other than CADI, are not evidence based. Lastly, it is essential that we promote inclusive partnerships where persons with IDD, family members, service providers, NGOs and government entities each have a voice. We cannot afford to wait any longer. 


\section{References}

Allen-Leigh, B. (2009) Estudio sobre discriminación y discapacidad mental e intelectual. [Study on Discrimination and Mental and Intellectual Disabilities.] Available at http://www.conapred.org.mx/ documentos_cedoc/E06-2009.pdf (accessed June 2016).

Allen-Leigh, B., Katz, G., Rangel-Eudave, G., et al (2008) View of Mexican family members on the autonomy of adolescents and adults with intellectual disability. Salud Pública de México, 50, s213-s221

Anderson, L. L., Humphries, K., McDermott, S., et al (2013) The state of the science of health and wellness for adults with intellectual and developmental disabilities. Intellectual and Developmental Disabilities, 51, 385-398.

Anuncian Moreno Valle y Teletón construcción de CRIT en Puebla (2010) Video, videoeconsulta, 6 December. Available at https:// www.youtube.com/watch?v=-4ZqCOKJVwY (accessed June 2016).

Cabrera, R. (2010) Teletón: el monopolio de la atención de la discapacidad. [Teletón: The Monopoly of Disability Care.] Emmequis. Available at http://www.m-x.com.mx/2012-12-02/teleton-elmonopolio-de-la-atencion-a-la-discapacidad (accessed June 2016).

Carulla, L. S., Reed, G. M., Vaez-Azizi, L. M., et al (2011) Intellectual developmental disorders: towards a new name, definition and framework for 'mental retardation/intellectual disability' in ICD-11. World Psychiatry, 10, 175-180.
Fujiura, G. T., Roccoforte, J. A. \& Braddock, D. (1994) Costs of family care for adults with mental retardation and related development disabilities. American Journal on Mental Retardation, 99, 250-261.

Harris, J. C. (2013) New terminology for mental retardation in DSM5 and ICD-11. Current Opinion in Psychiatry, 26, 260-262.

Huus, K., Granlund, M., Bornman, J., et al (2015) Human rights of children with intellectual disabilities: comparing self-ratings and proxy ratings. Child: Care, Health and Development, 41, 1010-1017.

Katz, G. \& Lazcano-Ponce, E. (2008) Sexuality in subjects with intellectual disability: an educational intervention proposal for parents and counselors in developing countries. Salud Pública de México, 50, s239-s254.

Katz, G., Rangel-Eudave, G., Allen-Leigh, B., et al (2008) A best practice in education and support services for independent living of intellectually disabled youth and adults in Mexico. Salud Pública de México, 50, s194-s204.

Lazcano-Ponce, E., Rangel-Eudave, G. \& Katz, G. (2008) Intellectual disability and its effects on society. Salud Pública de México, 50, s119-s120.

Maulik, P. K., Mascarenhas, M. N., Mathers, C. D., et al (2011) Prevalence of intellectual disability: a meta-analysis of populationbased studies. Research in Developmental Disabilities, 32, 419-436.

\section{PANDORA'S} BOX

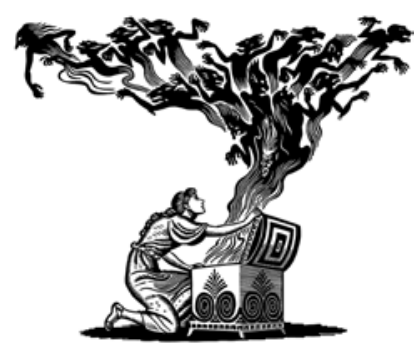

\section{Antidepressants - the trendy panacea but} how safe are they?

ccording to the Health and Social Care InforAmation Centre (HSCIC), antidepressant drugs are among the three most prescribed drug groups in the UK, alongside the statins and analgesics. One in 10 women, mostly of mature age and from deprived areas, are on antidepressant drugs. But let's not assume that these are all prescribed for the treatment of depression. A recent study by Wong et $a l$ in Canada, using data from electronic prescribing records by primary care physicians in Quebec, found that for only $55 \%$ of the prescriptions was the indication depressive disorder; among the rest the indications included anxiety, insomnia or pain, but also off-label indications such as migraine, menopausal vasomotor symptoms, attention-deficit/ hyperactivity disorder and digestive disorders.

There are understandable concerns about the outcomes of off-label prescribing and the evidence shows that there is an association with an increased risk of adverse events. Another study in Quebec, by Equale $e t$ al and published in January this year, found that off-label prescribing was associated with higher rates of adverse events than on-label prescribing. Interestingly, off-label prescribing where there was strong scientific evidence was associated with the same risk of adverse events as on-label prescribing! So let's not give up on off-label prescribing as yet but make sure the reasoning behind this has a good scientific basis.

Equale, T., Buckeridge, D. L., Verma, A., et al (2016) Association of off-label drug use and adverse drug events in an adult population. JAMA Internal Medicine, 176, 55-63. doi: 10.1001/ jamainternmed.2015.6058.

Wong, J., Motulsky, A., Buckeridge, D. L., et al (2016) Treatment indications for antidepressants prescribed in primary care in Quebec, Canada, 2006-2015. JAMA, 315, 2230-2232. doi:10.1001/ jama.2016.3445.PMID:27218634.

\section{One suicide is too many}

$\mathrm{M}$ local newspaper in London reports on average one suicide every 4-6 weeks; okay, it is a high-risk area, but is this acceptable? The UK's Office for National Statistics (ONS) reported a $2 \%$ reduction in suicide rates in 2014 but it should be noted that the year before there had been a $4 \%$ increase!

At the recent annual meeting of the American Psychiatric Association (APA), the issue of suicide was given special attention. Drs Shareh Ghani and Karen Chaney presented the Magellan programme, which they claimed brought suicide down to zero in the first 3 months and significantly reduced suicide rates in Arizona by $67 \%$ in the general population and by $42 \%$ among people with serious mental illness. They adopted Applied Suicide Intervention Skills Training (ASIST) to train staff in 12 out-patient centres. They claimed that their programme 'looks at suicide differently, as a systems issue, not a one therapist, one doctor issue. That's a big culture change.' The programme is 'quite laborious, but it is very effective'. They trained over $90 \%$ of the targeted workforce in ASIST and found a significant increase in the number of providers who 'felt strongly' they could engage and assist those with suicidal desire or intent. Key components of the programme include standardised suicide risk screening; if the screening is positive, a full assessment of suicide risk is conducted, and appropriate interventions are made to ensure safety, treatment, ongoing care and close follow-up. As part of the programme, a comprehensive clinical decision support tool is implemented in the electronic medical record.

The incoming APA President, Maria A. Oquendo, said, 'all suicides should be preventable, 